\title{
Epileptic spike-wave discharges in a spatially extended thalamocortical model
}

\author{
Peter N Taylor ${ }^{1 *}$, Yujiang Wang ${ }^{2}$, Gerold Baier ${ }^{3}$, Sydney S Cash ${ }^{4}$, Justin Dauwels ${ }^{1}$ \\ From Twenty Second Annual Computational Neuroscience Meeting: CNS*2013 \\ Paris, France. 13-18 July 2013
}

Generalised spike-wave discharges (SWD), detectable on the electroencephalogram (EEG), are a hallmark of typical absence seizures. Several mechanisms of transmission have been proposed for SWD seizures including the centrencephalic theory, the corticoreticular theory, and the cortical focus theory [1]. Experimental evidence suggests that seizures rapidly generalise through corticocortical and thalamo-cortical pathways from an excitable cortical 'focus' [1]. Further evidence for a cortical focus comes from recent experimental results which show
(A)
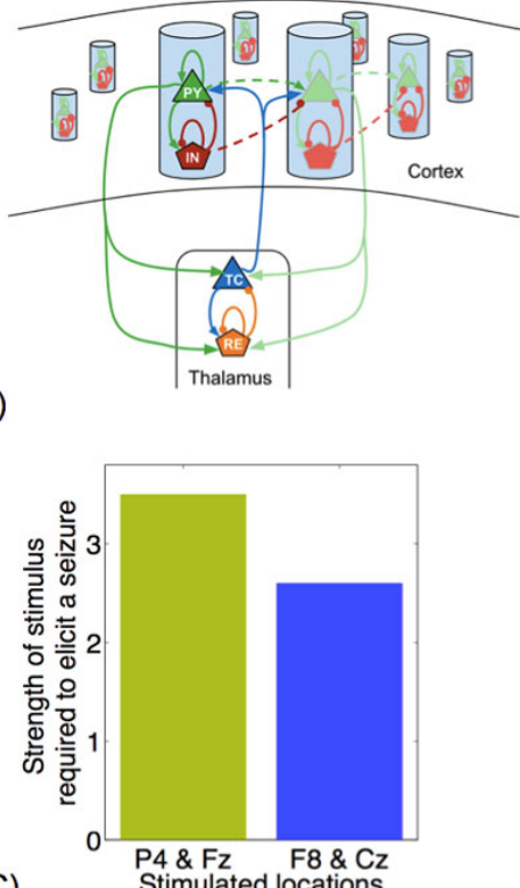

(B)
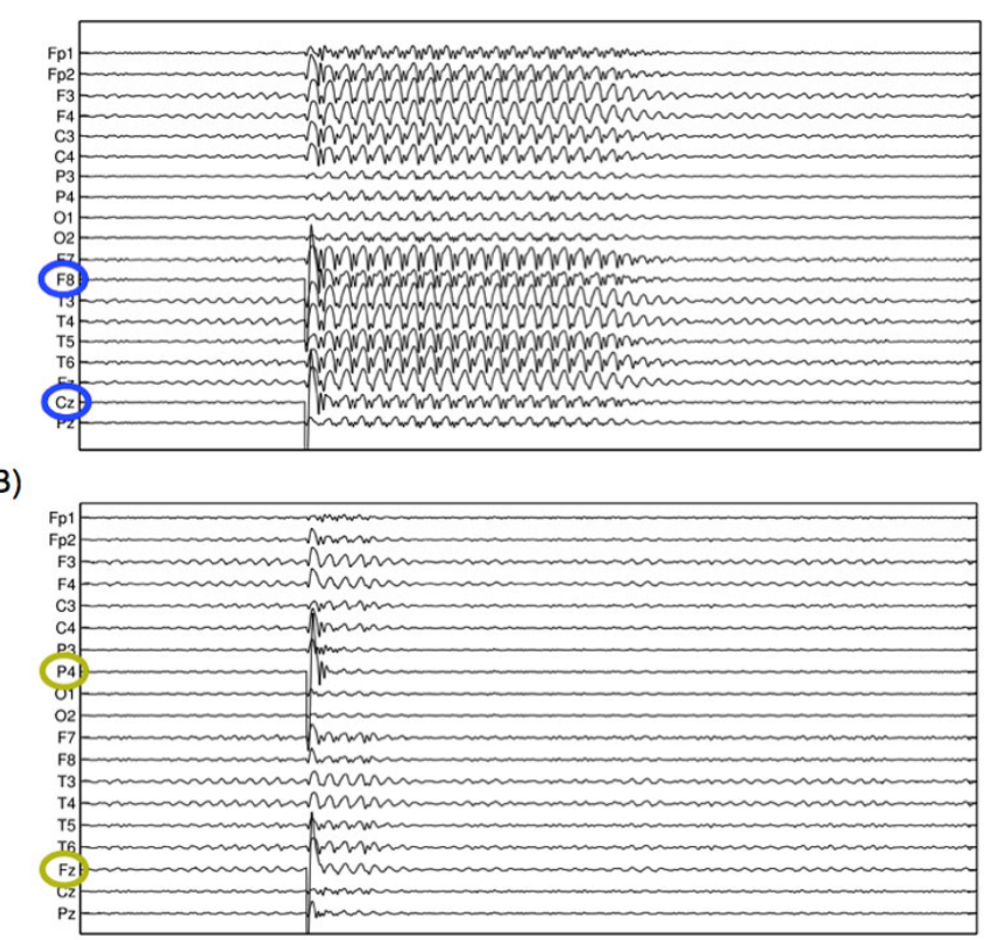

(C)

Figure 1 (A) Connectivity scheme of the model. (B) Top panel: Stimulus induced SWD seizure. Bottom panel: Stimulus induced short transient response (no seizure). (C) Minimum amplitude of stimulus required to initiate a seizure

\footnotetext{
* Correspondence: ptaylor@ntu.edu.sg

'School of Electrical \& Electronic Engineering, Nanyang Technological

University, Singapore

Full list of author information is available at the end of the article
} 
that stimulations to different cortical regions can elicit generalised SWD, however, the amplitude of the required stimulus varies from one region to another [2].

Based on known anatomical connectivity between the thalamus and cortex (Figure. 1A), we develop a macroscopic model of transitions between inter-ictal and ictal SW dynamics to investigate the cortical focus theory. Single pulse perturbations of sufficient amplitude can drive the model into the seizure state, i.e. the dynamics are excitable. Mechanistically, the stimuli transiently drive the cortical subsystem beyond a saddle-node bifurcation (c.f. [3]).

We extend the model to include multiple cortical compartments (using cortico-cortical connectivity inferred from patient EEG) and find that the threshold for an excitable response varies between cortical regions. Figure 1B (top panel) shows an exemplary time series where a stimulus is applied which results in a long seizure-like transient. In Figure 1B (bottom panel), the stimulation of other cortical compartments elicits only short responses. In agreement with [2] a stimulus of higher amplitude is required to elicit a seizure (Figure 1C). This shows that whilst thalamo-cortical connectivity is essential for SWD maintenance, cortico-cortical connectivity crucially influences the site of SWD initiation. The model provides evidence for the cortical focus theory, where specific cortical regions are more susceptible to producing generalised SWD seizure upon stimulation. This is strongly dependent on the patient specific heterogeneous cortico-cortical and thalamocortical connectivity.

\footnotetext{
Author details

${ }^{1}$ School of Electrical \& Electronic Engineering, Nanyang Technological University, Singapore. ${ }^{2}$ Manchester Interdisciplinary Biocentre, University of Manchester, UK. ${ }^{3}$ Centre for Organismal Studies, University of Heidelberg, Germany. ${ }^{4}$ Massachusetts General Hospital and Harvard Medical School, Cambridge, USA.
}

Published: 8 July 2013

\section{References}

1. Meeren H, van Luijtelaar G, Lopes da Silva F, Coenen A: Evolving concepts on the pathophysiology of absence seizures: the cortical focus theory. Arch Neurol 2005, 62(3):371-376.

2. Zheng T, Obrien T, Morris M, Reid C, Jovanovska V, OBrien P, van Raay L, Gandrathi A, Pinault D: Rhythmic neuronal activity in S2 somatosensory and insular cortices contribute to the initiation of absence-related spikeand-wave discharges. Epilepsia 2012, 53(11):1948-58.

3. Taylor PN, Baier G: A spatially extended model for macroscopic spikewave discharges. J Comput Neurosci 2011, 31(3):679-684.

doi:10.1186/1471-2202-14-S1-P87

Cite this article as: Taylor et al:: Epileptic spike-wave discharges in a spatially extended thalamocortical model. BMC Neuroscience 2013 14(Suppl 1):P87.

\section{Submit your next manuscript to BioMed Central and take full advantage of:}

- Convenient online submission

- Thorough peer review

- No space constraints or color figure charges

- Immediate publication on acceptance

- Inclusion in PubMed, CAS, Scopus and Google Scholar

- Research which is freely available for redistribution

Submit your manuscript at www.biomedcentral.com/submit
C Biomed Central 